\title{
Editorial
}

\section{Topics in Sponge Biology and Ecology}

Sponges are a dominant component of the fauna inhabiting hard substratum marine and freshwater environments across the world and there is increasing interest in sponges for a variety of reasons including their important functional roles [1], their biomass/abundance dominance in many locations [2], their economic value and their (or their bacterial symbionts) potential for producing bioactive compounds [3]. Even though the importance of sponges is well-recognized, for many scientists, sponges can represent a difficult group to work with for a number of reasons. Firstly, their taxonomy can be difficult and complex and despite major works [4] bringing together existing taxonomic information, they still remaining a difficult group to identify. Coupled with their complex taxonomy is the new information that is becoming increasingly available as a result of the application of molecular techniques to sponges, which are changing the way we think about their taxonomy [5]. Secondly, sponges are not easy to quantify, as they share characteristics with both colonial and solitary organisms. Sponge abundance can be quantified by counting the number of patches, measuring the area they occupy, by calculating their volume, or by using a combination of these methods. While these variables are perhaps easy to measure for some species, for others, such as thin crusts, this is not so easy. In addition, these different measurements provide different information on the nature of sponge assemblages, for example, volume provides an indication of the interaction between sponges and the water column, while area occupied provides data on the likely occurrence of spatial competition with other benthic organisms. Finally, sponges are relatively difficult to culture and maintain in laboratory conditions, which can make experimentation difficult. Despite these problems, there are still a large group of researchers focused on sponges.

One of the main reasons for the increasing interest in sponges is the range of important ecological functional roles that sponges fulfill. Functions can be categorised into main three areas: (a) impacts on substrate (including bioerosion, reef creation, and substrate stabilisation, consolidation and regeneration); (b) bentho-pelagic coupling (including carbon cycling, silicon cycling, oxygen depletion and nitrogen cycling); and (c) associations with other organisms (facilitating primary production, secondary production, provision of microhabitat, enhanced predation protection, survival success, range expansions and camouflage though association with sponges, sponges as a settlement substrate, disrupting near-boundary and reef level flow regimes, sponges as agents of biological disturbance, sponges as releasers of chemicals and sponges as tools for other organisms).

This special issue of the Open Marine Biology Journal represents the culmination of the work on many sponge researchers and contains papers on a diverse array of topics including sponge reproduction, ecology, biodiversity and aquaculture. There is a considerable amount of information available for deepwater $(>200 \mathrm{~m})$ and shallow water $(<30 \mathrm{~m})$ sponge assemblages, but this special issue begins with a description of the sponge gardens at a depth of 18-100m on Ningaloo Reef, Western Australia, including some fantastic images of the sponge dominated environments. This apparent 'gap' between deepwater and shallow water research is clearly highlighted in this paper, as these environments are dominated by very high sponge biomass and diversity. This deep water research is followed by three papers examining the spatial distribution of sponge assemblages in shallow waters $(<30 \mathrm{~m})$. The spatial separation of these studies is large including one study in New Zealand, another in Indonesia and the final one at Palmyra Atoll in the central Pacific. These studies all highlight the considerable amount of variability present in sponge assemblages, and how such patterns can be explained by a range of biological and physical factors. The ecology section concludes with the first description of the sponge-feeding fishes on the Mexican coast, which compliments previous work in the region on how physical factors influence sponge assemblages [6].

The next section of this sponge special issue sheds new light on the reproductive ecology of two sponge species, describing the reproductive cycle of Hymeniacidon perlevis living in different environments, and the spermcasting ability of Amphimedon queenslandica. The final paper in this section deals with sponge feeding, with this study being the first to investigate the natural diet of calcareous sponges in temperate rocky subtidal reefs using flow cytometry, since most previous work has focused on demosponges. In the final series of papers in this issue, the authors deal with the problem described above regarding the 
aquaculture of sponges, with the authors describing how sponges might be cultured in open environments, rather than in laboratories. Although we know that sponges contain a vast array of novel compounds, we still know very little about their ecological significance. The functional significance of carotenoids are considered in final paper this section, with evidence suggesting that solar radiation is an important factor in shaping carotenoid profiles of Clathrina prolifera, and that these compounds are probably beneficial to the sponge. The final paper of this issue provides new information on a freshwater sponge freshwater sponge discovered in the California Delta. While the Open Marine Biology Journal is of course focused on marine environments, I felt that freshwater sponge researchers might feel excluding from our occasional sponge special issues as they are published in marine journals, so I thought it appropriate to extend this issue to include freshwater sponges as well, as these sponges are very much understudied.

This sponge special issue is the first to be published in an open access online journal and it is my hope that the nature of this journal will enable this new information to be widely disseminated and accessible to sponge and non-sponge researchers alike across the world.

\section{Dr. James J. Bell}

Centre for Marine Environmental and Economic Research

School of Biological Sciences

Victoria University of Wellington

P.O. Box 600, Wellington

New Zealand

Tel: +64-4-463-5339

E-mail: james.bell@vuw.ac.nz

\section{REFERENCES}

[1] Bell JJ. The functional roles of marine sponges. Estuar Coast Shelf Sci 2008; 79(3): 341-53.

[2] Bell JJ. The ecology of sponges at Lough Hyne Marine Nature Reserve; past, present and future perspectives. J Mar Biol Assoc UK 2007; 87: 165568.

[3] Taylor MW, Radax R, Steger D, Wagner M. Sponge-associated microorganisms: evolution, ecology and biotechnological potential. Microbiol Mol Biol Rev 2007; 71, 295-347.

[4] Hooper JNA, van Soest RWM. Systema Porifera: A Guide to the Classification of Sponges. Springer, US. 2002.

[5] Borchiellini C, Chombard c, Lafay B, Boury-Esnault, N. Molecular systematics of sponges (Porifera). Hydrobiologia $2000 ; 420: 15-27$.

[6] Carballo JL. Effect of natural sedimentation on the structure of tropical sponge assemblages. Ecoscience 2006; 13: 119-30.

(C) James J. Bell; Licensee Bentham Open.

This is an open access article licensed under the terms of the Creative Commons Attribution Non-Commercial License (http://creativecommons.org/licenses/by$\mathrm{nc} / 3.0 /$ ), which permits unrestricted, non-commercial use, distribution and reproduction in any medium, provided the work is properly cited. 